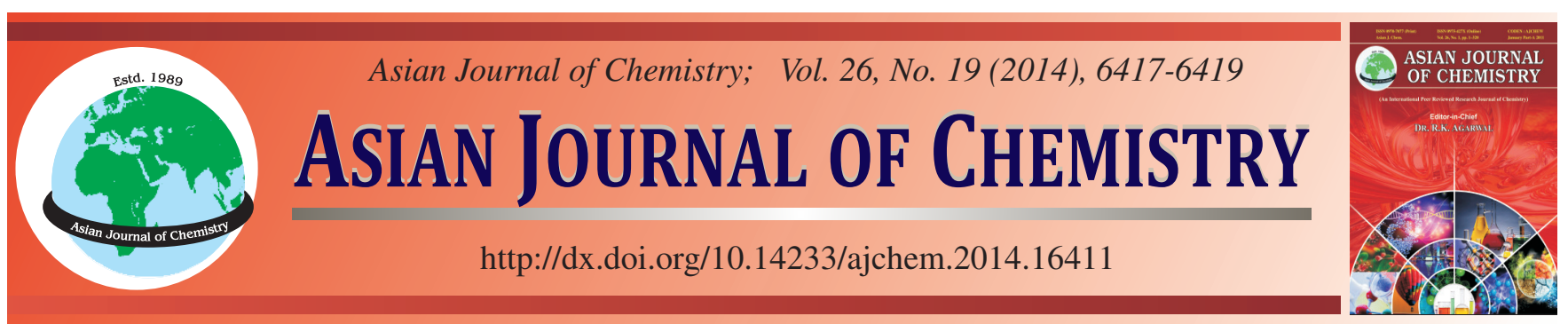

\title{
Design and Synthesis of New Steroid-Oxazin Derivative Using Some Strategies
}

Figueroa-Valverde Lauro ${ }^{1, *}$, Díaz-Cedillo Francisco ${ }^{2}$, García-Cervera Elodia ${ }^{1}$, Pool-Gómez Eduardo ${ }^{1}$, Rosas-Nexticapa Marcela ${ }^{3}$, López-Ramos Maria ${ }^{1}$, Hau-Heredia Lenin ${ }^{1}$ and Sarabia-Alcocer Betty ${ }^{4}$

${ }^{1}$ Laboratory of Pharmaco-Chemistry, Faculty of Chemical Biological Sciences, University Autonomous of Campeche, Av. Agustín Melgar
s/n, Col Buenavista C.P. 24039 Campeche Cam., México
${ }^{2}$ Facultad de Nutrición, Universidad Veracruzana, Médicos y Odontologos s/n C.P. 91010, Unidad del Bosque Xalapa, Veracruz, México
${ }^{3}$ Escuela Nacional de Ciencias Biológicas del Instituto Politécnico Nacional. Prol. Carpio y Plan de Ayala s/n Col. Santo Tomas, México, D.F.
C.P. 11340
${ }^{4}$ Faculty of Medicine, University Autonomous of Campeche, Av. Patricio Trueba deRegil s/n, Col Lindavista C.P. 24090 Campeche Cam., México

*Corresponding author: Tel: +981 8119800, Ext. 3070105; E-mail: lauro_1999@yahoo.com

Received: 23 September 2013;

Accepted: 13 January 2014;

Published online: 16 September 2014;

AJC-15930

\begin{abstract}
In this study, a steroid-oxazin derivative was synthesized using several strategies; the first stage involve the reaction of $\beta$-naphthol with ethylenediamine in presence of formaldehyde to form the compound 3 (3-(1H-naphtho[1,2-e][1,3]oxazin-2(3H)-yl)propan-1-amine). The second stage was achieved by reaction of $\mathbf{3}$ with dehydroisoandrosterone 3 -sulfate to form the compound $\mathbf{5}$ (10,13-dimethyl-17-[2(1H-naphtho[1,2-e][1,3] oxazin-2-yl)-ethylimino]-2,3,4,7,8,9,10,11,12,13,14,15,16,17-tetradecahydro-1H-cyclopenta[a]phenanthrene-3sulfonic acid) using boric acid as catalyst. Finally, the third stage involve the synthesis of 17-\{(3-chloro-2-oxo-cyclobutyl)-[2-(1Hnaphtho[1,2-e][1,3]oxazin-2-yl)-ethyl]amino $-10,13$-dimethyl-2,3,4,7,8,9,10,11,12,13,14,15,16,17-tetradecahydro- $1 \mathrm{H}$ cyclopenta[a]phenanthrene-3-sulfonic acid (7) by reaction of 5 with chloroacetyl chloride in presence of triethylamine. The structure of compounds obtained was confirmed by elemental analysis, spectroscopy and spectrometry data. In conclusion, this method offers some advantages such as good yields, simple procedure, low cost and ease of workup.
\end{abstract}

Keywords: Steroid, Oxazin, $\beta$-naphthol, Ethylenediamine.

\section{INTRODUCTION}

Oxazine derivatives are very important heterocyclic compounds with several biological activities ${ }^{1,2}$. Therefore, diverse oxazine derivatives have been developed; e.g., the synthesis of 1,2-dihydro-1-arylnaphtho[1,2-e][1,3]oxazine3 -one derivatives ${ }^{3}$ using the three-component system ( $\beta$ naphthol, benzaldehyde and urea) in presence of $\mathrm{HClO} 4-\mathrm{SiO}_{2}$. Other studies showed the condensation of 2-naphthol with heteroarylaldehydes or substituted benzaldehydes in the presence of ammonia ${ }^{4}$. Also, severalsteroid-oxazine derivatives have been developed, such as the compound 4-aza-4-ethyl$17 \beta$-hydroxy-2-oxa-5a-estrane which was prepared by the reaction of 4-aza-1, 17 $\beta$-dihydroxy-1,2-seco-5 $\alpha$-estranewith paraformaldehyde in benzene to reflux ${ }^{5}$. Other reports showed the synthesis of a steroid-oxazin derivative $\left(5^{\prime} \mathrm{R}-3 \beta\right.$-acetoxy$17 \beta$-[2-phenyl-4,5-dihydro-oxazol-5-yl]androst-5-ene) by the reaction of (20 R)-3 $\beta$-acetoxy-21-azidopregn-5-en-20-ol with benzaldehyde using $\mathrm{BF}_{3} \cdot \mathrm{OEt}_{2}$ as catalyst ${ }^{6}$. In addition, other experimental data showed the synthesis of N-methyl-3 $3,5-$

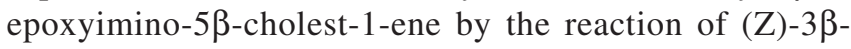

acetoxy-5,10-secocholest-1(10)-en-5-one with N-methylhydroxyl-aminehydro-chloride ${ }^{7}$. Other studies showed the synthesis of 2'-phenyl)-androstano-[16,17-e]-3',6'-dihydro1 ',2'-oxazineby the reaction of 10,13-dimethyl-17-vynyl2,34,5,6,7,8,9,10,11,12,13,14,15-tetra-decahydro- $1 H$ cyclopenta[a]phenanthrene with nitrosobenzene ${ }^{8}$. All these experimental results show several procedures which are available for synthesis of several oxazin-derivatives; nevertheless, expensive reagents and special conditions are required. Therefore, in this study a new steroid-oxazin derivative was synthetized using some strategies.

\section{EXPERIMENTAL}

The compounds evaluated in this study were purchased from Sigma-Aldrich Co. Ltd. The melting points for the different compounds were determined on an Electrothermal (900 model). Infrared spectra (IR) were recorded using $\mathrm{KBr}$ pellets on a Perkin Elmer Lambda 40 spectrometer. ${ }^{1} \mathrm{H}$ and ${ }^{13} \mathrm{C}$ NMR spectra were recorded on a Varian VXR-300/5 FT NMR spectrometer at 300 and $75.4 \mathrm{MHz}$ in $\mathrm{CDCl}_{3}$ using TMS as 
internal standard. EIMS spectra were obtained with a Finnigan Trace GCPolaris Q. spectrometer. Elementary analysis data were acquired from a Perkin Elmer Ser. II CHNS/0 2400 elemental analyzer.

Synthesis of 3-(1H-naphtho[1,2-e][1,3]oxazin-2(3H)yl)propan-1-amine (3) (Fig. 1): A solution of $\beta$-naphthol (200 $\mathrm{mg}, 1.39 \mathrm{mmol})$, ethylenediamine (172 $\mathrm{mg}, 2.78 \mathrm{mmol})$ and $1 \mathrm{~mL}$ of formaldehyde in $10 \mathrm{~mL}$ of methanol was stirring to reflux for $6 \mathrm{~h}$. The reaction mixture was evaporated to dryness under reduced pressure. The obtained solid was washed with water, yielding $70 \%$ of product, m.p. $160-162{ }^{\circ} \mathrm{C}$; IR $(\mathrm{KBr}$, $\left.v_{\max }, \mathrm{cm}^{-1}\right)=3380,1170,1158 ;{ }^{1} \mathrm{H}$ NMR $\left(300 \mathrm{MHz}, \mathrm{CDCl}_{3}\right)$ $\delta_{\mathrm{H}}: 1.68(\mathrm{t}, 2 \mathrm{H}, J=6.70), 1.70(\operatorname{broad}, 2 \mathrm{H}), 252(\mathrm{~m}, 2 \mathrm{H}), 2.56$ (t, 2H, 6.70), 4.10-4.20 (m, 2H), 4.80-4.82 (m, 2H), 7.08-7.78 $(\mathrm{m}, 6 \mathrm{H}) \mathrm{ppm} .{ }^{13} \mathrm{C} \mathrm{NMR}\left(75.4 \mathrm{~Hz}, \mathrm{CDCl}_{3}\right) \delta: 30.68(\mathrm{C}-16), 39.30$ (C-17), 50.78 (C-4), 53.66 (C-15), 82 (C-2), 111.20 (C-5), 117.80 (C-7), 120.34 (C-11), 123.30 (C-13), 126.24 (C-12), 126.60 (C-10), 127.88 (C-14), 128.34 (C-8), 133.10 (C-9), 152.34 (C-6) ppm. EI-MS m/z: $242.10(\mathrm{M}+10)$. Anal. Calcd. for $\mathrm{C}_{15} \mathrm{H}_{18} \mathrm{~N}_{2} \mathrm{O}$ : C, 74.35; H, 7.49; N, 11.56; O, 6.60. Found: C, 74.32; H, 7.48.

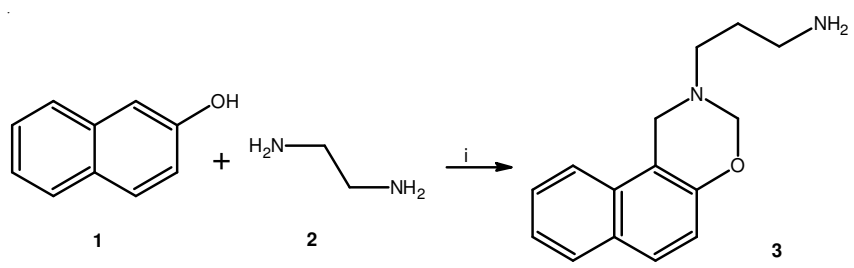

Fig. 1. Synthesis of 3-(1H-naphtho[1,2-e][1,3]oxazin-2(3H)-yl)propan-1amine (3). Reaction of $\beta$-naphtol (1) with ethylenediamine (2) to form the compound 3 . $\mathrm{i}=$ formaldehyde/methanol

Synthesis of 10,13-dimethyl-17-[2-(1H-naphtho[1,2e][1,3]oxazin-2-yl)-ethylimino]-2,3,4,7,8,9,10,11,12,13, $14,15,16,17$-tetradecahydro- $1 H$-cyclopenta[a]phenanthrene-3-sulfonic acid (5) (Fig. 2): A solution of compound 3 (100 mg, $0.41 \mathrm{mmol}$ ), dehydroisoandrosterone 3-sulfate (146 $\mathrm{mg}, 0.41 \mathrm{mmol})$ and boric acid $(50 \mathrm{mg}, 0.82 \mathrm{mmol})$ in $10 \mathrm{~mL}$ of $\mathrm{CHCl}_{3}: \mathrm{CH}_{3} \mathrm{OH}$ (3:1) was stirring to room temperature for $48 \mathrm{~h}$. The reaction mixture was evaporated to dryness under reduced pressure. The obtained solid was washed with water, yielding $66 \%$ of product, m.p. $180{ }^{\circ} \mathrm{C}$; IR $\left(\mathrm{KBr}, v_{\max }, \mathrm{cm}^{-1}\right)=$ 3320, 1172, 1160; ${ }^{1} \mathrm{H}$ NMR $\left(300 \mathrm{MHz}, \mathrm{CDCl}_{3}\right) \delta_{\mathrm{H}}: 0.98(\mathrm{~s}$, $3 \mathrm{H}), 1.01(\mathrm{~s}, 3 \mathrm{H}), 1.05-1.66(\mathrm{~m}, 5 \mathrm{H}), 1.74-1.90(\mathrm{~m}, 4 \mathrm{H})$, 2.04-2.50 (m, 9H), $2.66(\mathrm{t}, 2 \mathrm{H}, J=7.0), 2.70(\mathrm{~m}, 1 \mathrm{H}), 3.52(\mathrm{t}$, $2 \mathrm{H}, J=7.0), 3.74(\mathrm{~m}, 1 \mathrm{H}), 4.30-4.40(\mathrm{~m}, 2 \mathrm{H}), 5.00-5.10(\mathrm{~m}$, $2 \mathrm{H}), 5.54(\mathrm{~d}, 1 \mathrm{H}, J=5.35), 7.02-7.70(\mathrm{~m}, 6 \mathrm{H}), 8.22$ (broad, $1 \mathrm{H}) \mathrm{ppm} .{ }^{13} \mathrm{C}$ NMR $\left(75.4 \mathrm{~Hz}, \mathrm{CDCl}_{3}\right) \delta: 15.92(\mathrm{C}-35), 19.20$ (C-36), 20.50 (C-23), 21.80 (C-26), 25.74 (C-32), 27.50 (C-25), 29.64 (C-21), 31.70 (C-27), 32.20 (C-24), 32.91 (C-34), 34.71 (C-31), 39.44 (C-30), 41.21 (C-19), 47.22 (C-22), 50.40 (C-4), 50.80 (C-16), 53.66 (C-20), 53.80 (C-15), 55.12 (C-33), 82.33 (C-2), 113.58 (C-5), 118.40 (C-7), 120.82(C-1), 122.30 (C-28), 123.32 (C-13), 126.30 (C-12), 127.90 (C-14), 128.40 (C-8), 128.78 (C-10), 131.66 (C-9), 137.30 (C-29), 151.70 (C-6), 176.80 (C-18) ppm. EI-MS m/z: 562.26 $(\mathrm{M}+10)$. Anal. Calcd. for $\mathrm{C}_{33} \mathrm{H}_{42} \mathrm{~N}_{2} \mathrm{O}_{4} \mathrm{~S}: \mathrm{C}, 70.43 ; \mathrm{H}$, 7.52; N, 4.98; O, 11.37; S, 5.70. Found: C, 70.50; H, 7.50.

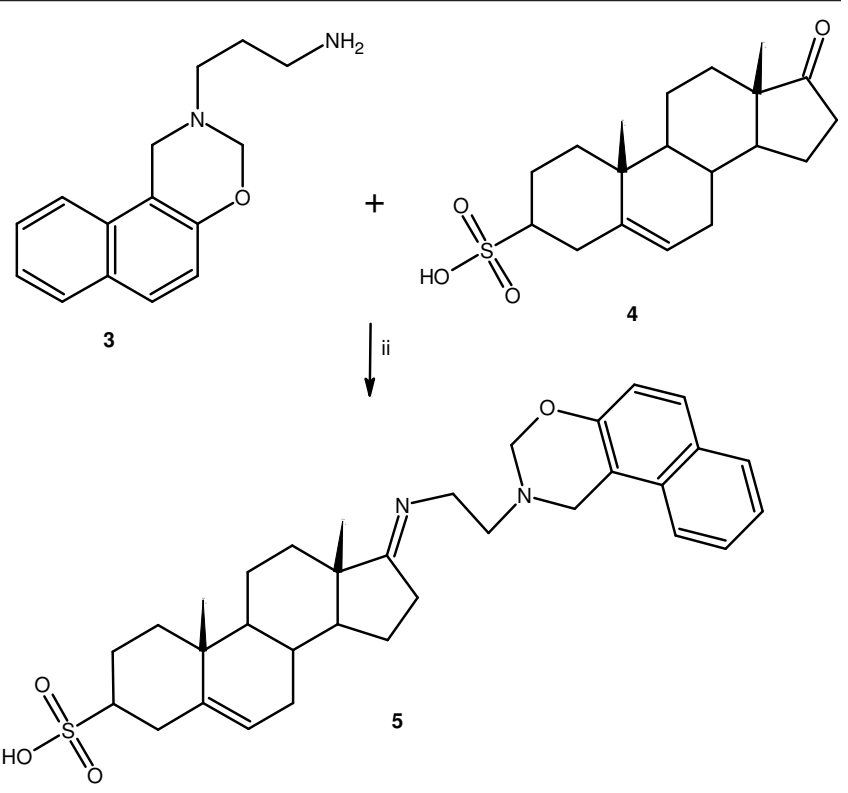

Fig. 2. Synthesis of 10,13-dimethyl-17-[2-(1H-naphto[1,2-e][1,3]oxazin2-yl)-ethylimino]-2,3,4,7,8,9,10,11,12,13,14,15,16,17-tetradecahydro- $1 H$-cyclopenta[a]phenanthrene-3-sulfonic acid (5). Reaction of 3-(1H-naphtho[1,2-e][1,3]oxazin-2(3H)-yl)propan-1-amine (3) with dehydroisoandrosterone 3 -sulfate (4) to form the compound 5. ii $=$ boric $\mathrm{acid} / \mathrm{methanol}$

Synthesis of 17-\{(3-chloro-2-oxo-cyclobutyl)-[2-(1Hnaphtho[1,2-e][1,3]oxazin-2-yl)-ethyl]amino $\}$-10,13dimethyl-2,3,4,7,8,9,10,11,12,13,14,15,16,17-tetradecahydro-1H-cyclopenta[a]phenanthrene-3-sulfonic acid (7) (Fig. 3): A solution of compound 5 (100 mg, $0.18 \mathrm{mmol}$ ), chloroacetyl chloride $(29 \mu \mathrm{L}, 0.36 \mathrm{mmol})$ and triethylamine $(50 \mu \mathrm{L}, 0.36 \mathrm{mmol})$ in $10 \mathrm{~mL}$ of methanol was stirring to room temperature for $48 \mathrm{~h}$. The reaction mixture was evaporated to dryness under reduced pressure. The obtained solid was washed with water, yielding $70 \%$ m.p. $220-222{ }^{\circ} \mathrm{C}$; IR (KBr, $v_{\max }$, $\left.\mathrm{cm}^{-1}\right)=1720,1345,1164 ;{ }^{1} \mathrm{H}$ NMR $\left(300 \mathrm{MHz}, \mathrm{CDCl}_{3}\right) \delta_{\mathrm{H}}$ :

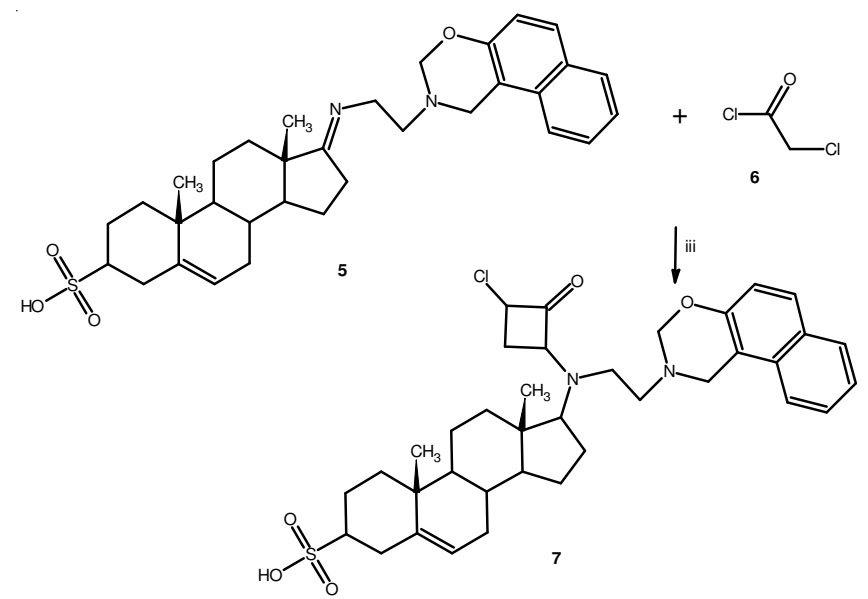

Fig. 3. Synthesis of 17-\{(3-chloro-2-oxo-cyclobutyl)-[2-(1H-naphto[1,2e][1,3]oxazin-2-yl)-ethyl]amino $\}$-10,13-dimethyl-2,3,4,7,8,9,10, $11,12,13,14,15,16,17$-tetradecahydro- $1 H$-cyclopenta[a]phenanthrene-3-sulfonic acid (7). Reaction of 10,13-dimethyl-17-[2-(1Hnaphto[1,2-e][1,3] oxazin-2-yl)-ethylimino] 2,3,4,7,8,9,10,11,12,13, $14,15,16,17$-tetradecahydro- $1 H$-cyclopenta-[a]phenanthrene-3sulfonic acid (5) with chloroacetyl chloride (6) to form the compound 7. iii $=$ triethylamine/methanol 
$0.72(\mathrm{~s}, 3 \mathrm{H}), 0.86(\mathrm{~m}, 1 \mathrm{H}), 1.00(\mathrm{~s}, 3 \mathrm{H}), 1.10-1.60(\mathrm{~m}, 9 \mathrm{H})$, 1.66-1.70 (m, 2H), $1.68(\mathrm{~m}, 1 \mathrm{H}), 1.82(\mathrm{~m}, 1 \mathrm{H}), 1.96(\mathrm{~m}, 1 \mathrm{H})$, 2.00-2.42 (m, 6H), $2.50(\mathrm{t}, 1 \mathrm{H}, J=6.51), 2.52(\mathrm{~m}, 1 \mathrm{H}), 2.56$ $(\mathrm{t}, 1 \mathrm{H}, J=6.51), 3.10(\mathrm{t}, 2 \mathrm{H}, J=6.51), 3.62(\mathrm{~m}, 1 \mathrm{H}), 3.70(\mathrm{~m}$, $1 \mathrm{H}), 4.30-4.41(\mathrm{~m}, 2 \mathrm{H}), 4.58(\mathrm{~m}, 1 \mathrm{H}), 5.00-5.10(\mathrm{~m}, 2 \mathrm{H}), 5.56$ $(\mathrm{m}, 1 \mathrm{H}), 7.00-7.78(\mathrm{~m}, 6 \mathrm{H}), 8.16$ (broad, $1 \mathrm{H}) \mathrm{ppm} .{ }^{13} \mathrm{C} \mathrm{NMR}$ $\left(75.4 \mathrm{~Hz}, \mathrm{CDCl}_{3}\right)$ $\delta: 16.58(\mathrm{C}-39), 19.22(\mathrm{C}-40), 21.02(\mathrm{C}-$ 23), 25.18 (C-26), 25.70 (C-32), 27.32 (C-25), 31.48 (C-21), 31.58 (C-27), 32.70 (C-36), 32.90 (C-34), 34.17 (C-31), 36.40 (C-24), 39.40 (C-30), 46.48 (C-19), 49.90 (C-15), 50.33 (C4), 50.46 (C-16), 52.34 (C-22), 53.36 (C-20), 56.12 (C-33), 62.86 (C-37), 67.70 (C-18), 72.28 (C-35), 82.40 (C-2), 111.28 (C-5), 118.40 (C-7), 120.78 (C-11), 122.30 (C-28), 123.36 (C-13), 126.30 (C-12), 127.90 (C-14), 128.40 (C-8), 128.80 (C-10), 131.66 (C-9), 137.28 (C-29), 151.70 (C-6), 202.10 (C-38) ppm.EI-MS m/z: $666.28(\mathrm{M}+10)$. Anal. Calcd. for $\mathrm{C}_{37} \mathrm{H}_{47} \mathrm{ClN}_{2} \mathrm{O}_{5} \mathrm{~S}$ : C, 66.60; H, 7.10; Cl, 5.31; N, 4.20; O, 11.99; S, 4.81. Found: C, 66.56; H, 7.08.

\section{RESULTS AND DISCUSSION}

In this study we report a straight forward route for synthesis of steroid-oxazin derivative (7) using several strategies. It is noteworthy that there are studies which indicate a convenient route for the preparation of oxazin-derivatives by the reaction of substituted phenols with formaldehyde and primary aliphatic amines ${ }^{9,10}$. Therefore, in first stage was synthetized the compound 3-(1H-naphtho[1,2-e][1,3]oxazin-2(3H)-yl)propan-1amine (3) by the reaction of $\beta$-naphthol and ethylenediamine in presence of formaldehyde. The ${ }^{1} \mathrm{H}$ NMR spectrum of $\mathbf{3}$ shows signals at $1.68,2.52-2.56 \mathrm{ppm}$ for methylene groups involved in the arm bound to both amino groups; at $1.70 \mathrm{ppm}$ for amino group; at 4.10-4.82 ppm for oxazine ring; at 7.08$7.78 \mathrm{ppm}$ for phenyl groups. Other data indicate that ${ }^{13} \mathrm{C}$ NMR spectrum of $\mathbf{3}$ contains peaks at 30.68-39.30 and $53.66 \mathrm{ppm}$ for methylene groups involved in the arm bound to both amino groups; at 53.66-11.20 ppm for oxazine ring; at 117.80-152.34 ppm for phenyl groups. Finally, the presence of compound $\mathbf{3}$ was further confirmed from mass spectrum which showed a molecular ion at $m / z, 242^{10}$.

On the other hand, in the second stage was achieved by reaction of the compound $\mathbf{3}$ with dehydro iso and roster one 3 -sulfate resulting animino bond formation involved in the compound 5 (10,13-dimethyl-17-[2-(1H-naphtho[1,2e][1,3]oxazin-2-yl)-ethylimino]-2,3,4,7,8,9,10,11,12,13,14, 15,16,17-tetradeca-hydro- $1 H$-cyclopenta[a]phenanthrene-3sulfonic acid). It is important to mention that many procedures for the synthesis of imino groups are described in the literature ${ }^{11-13}$; nevertheless, in this study boric acid was used as a catalyst, because it is not an expensive reagent and no special conditions for its use are required ${ }^{14}$. The ${ }^{1} \mathrm{H}$ NMR spectrums of $\mathbf{5}$ shows signals at 0.98 and 1 for methyl groups; 1.05-2.50, $2.70,3.74$ and $5.54 \mathrm{ppm}$ for protons involved steroid nucleus; at 2.66 and $3.52 \mathrm{ppm}$ for methylene groups involved in the arm bound to both amino groups; at 4.30-5.09 ppm for oxazine ring; at 7.02-7.70 ppm for phenyl groups; at 8.22 for hydroxyl group. Other results indicate that ${ }^{13} \mathrm{C}$ NMR spectrum of 5 contains peaks at 15.92 and 19.20 ppm for methyl groups; at
20.50-47.22, 53.66, 55.12, 122.30 and $137.30 \mathrm{ppm}$ for protons involved in steroid nucleus; at 50.40, 82.30-113.58 ppm for methylene groups of oxazine ring; at 118.40-120.82, 123.32131.66 and $151.70 \mathrm{ppm}$ for phenyl groups; at $176.68 \mathrm{ppm}$ for imino group. Finally, the presence of compound 5 was further confirmed from mass spectrum which showed a molecular ion at $m / z$ 562.26.

The third stage step was achieved by the reaction of $\mathbf{5}$ with chloroacetyl chloride to form a cyclobutanonegroup involved in compound 7. It is important to mention that many procedures for the formation of cyclobutanone derivatives are known in the literature ${ }^{15-18}$, nevertheless, expensive reagents and special conditions are required. Therefore, in this study chloroacetyl chloride was used to form a cyclobutanonegroup involved in the compound 7. The ${ }^{1} \mathrm{H}$ NMR spectrum of compound 7 shows signals at 0.72 and $1 \mathrm{ppm}$ for methyl groups; at $0.86,1.10$ $1.70,1.82,2.00-2.42,2.52,3.70$ and $5.56 \mathrm{ppm}$; at 1.68, 1.96, 362 and $4.58 \mathrm{ppm}$ for cyclobutanone group; at 2.50, 2.56 and $3.10 \mathrm{ppm}$ for arm bound to both amino groups; at 4.30-4.41 and 5.00-5.10 ppm for oxazine ring; at 7.02-7.78 ppm for phenyl groups; at $8.16 \mathrm{ppm}$ for hydroxyl group.Other data indicate that ${ }^{13} \mathrm{C}$ NMR spectrum of 7 contains peaks at 16.58 and $19.22 \mathrm{ppm}$ for methyl groups; at 21.02-31.58, 32.90-46.48, 52.34-56.12, 67.70, 122.38 and $137.22 \mathrm{ppm}$ for steroid nucleus; at 32.70, 62.86 and $72.28 \mathrm{ppm}$ for cyclobutanone ring; at 49.90 and $50.46 \mathrm{ppm}$ for arm bound to both amino groups; at 50.38 and $82.40-11.28$ ppm for oxazine group; at 118.40-120.78, 123.36-131.66 and 151.70 ppm for phenyl groups; at 202.10 for ketone group. Finally, the presence of compound 7 was further confirmed from mass spectrum which showed a molecular ion at $m / z$ 666.20.

\section{REFERENCES}

1. M. Kuehne, E.A. Konopka and B.F. Lambert, J. Med. Chem., 5, 281 (1962).

2. A. Chaskar, V. Vyavhare, V. Padalkar, K. Phatangare and H. Deokar, J. Serb. Chem. Soc., 76, 21 (2011).

3. H. Abbastabar Ahangar, G.H. Mahdavinia, K. Marjani and A. Hafezian, J. Iran. Chem. Soc., 7, 770 (2010).

4. Z. Turgut, E. Pelit and A. Köycü, Molecules, 12, 345 (2007).

5. D.M. Piatak and E. Caspi, J. Org. Chem., 31, 3935 (1966).

6. D. Ondré, J. Wölfling, I. Tóth, M. Szécsi, J. Julesz and G. Schneider, Steroids, 74, 1025 (2009).

7. M. Rajkovic, L. Lorenc, I. Juranic, Z. Vitnik and M. Mihailovic, Tetrahedron, 55, 6681 (1999).

8. R. Skoda-Földes, K. Vándor, L. Kollár, J. Horváth and Z. Tuba, J. Org. Chem., 64, 5921 (1999).

9. W.J. Burke, R.P. Smith and C. Weatherbee, J. Am. Chem. Soc., 74, 602 (1952).

10. W.J. Burke, M.J. Kolbezen and C.W. Stephens, J. Am. Chem. Soc., 74, 3601 (1952).

11. A. Shirayev, I. Moiseev and S. Karpeev, Arkivoc, 199 (2004).

12. D. Uppiah, M. Bhowon and S. Jhaumeer, E-J. Chem, 6, 195 (2009).

13. M. Hania, E- J. Chem., 6, 629 (2009).

14. L. Figueroa-Valverde, F. Díaz-Cedillo, E. García-Cervera, E. PoolGómez and M. López-Ramos, Bulgarian Chem. Comm, 45, 71 (2013).

15. G.K. Kole, G.K. Tan and J.J. Vittal, Org. Lett., 12, 128 (2010).

16. J. Panda and S. Ghosh, Tetrahedron Lett., 40, 6693 (1999).

17. G.K. Kole, G.K. Tan and J.J. Vittal, J. Org. Chem., 76, 7860 (2011).

18. Y. Okada, T. Minami, S. Yahiro and K. Akinaga, J. Org. Chem., 54, 974 (1989). 